\title{
International intelligibility of Nigerian English: The Vowel Length Factor
}

\section{Fiyinfolu Olubunmi Idowu, PhD, MA}

London Brunel Int'l College, Brunel University, Uxbridge, Middlesex, United Kingdom

\begin{abstract}
The study examines the phonological intelligibility of Nigerian speakers of English. Specifically, it investigates the extent to which the length of vowels in the speech of Nigerian Speakers of English affects their intelligibility to speakers from different contexts. 100 evaluators, (international listeners made up of non-Nigerian speakers) transcribed six speech samples from six audio podcasts in which Nigerian speakers delivered speeches. The transcription of the different speech samples served to assess intelligibility at pronunciation level. Results revealed that the length of vowels is critical for maintaining intelligibility in international contexts.
\end{abstract}

Keywords: English as a lingua franca, intelligibility, vowel length, Nigerian English, pronunciation teaching

\section{Introduction}

Some researchers claim that some aspects of pronunciation are far more consequential to the maintenance of mutual intelligibility in English interactions than others (Jenkins 2000; 2007; Walker 2010; Deterding 2012; O'Neal 2015; Deterding and Mohamad 2016). Whilst there is evidence that segmental features of pronunciation cause intelligibility breakdown (Deterding, 2011; Zhang, 2013; Idowu, 2019), there is no widespread agreement on the particular aspects of pronunciation that are most consequential (O’Neal, 2015). Many ELF scholars claim that vowel length is critical for maintaining intelligibility (e.g. Jenkins, 1995; Jenkins, 2002; 2010) while some other ELF researchers using observations of recorded ELF interactions and ethnographic methods, argue that the length of a vowel is not very important to the maintenance of mutual intelligibility (Deterding 2013). Therefore, although studies (such as Deterding, 2013; Zhang, 2013; O'Neal 2015) agree that some segmental features of pronunciation cause intelligibility breakdown, there is no agreement about the specific segmental 
features that cause problems. Against this background, the discussion of findings here is an important step towards addressing this relative paucity of knowledge. Specifically, this study investigates whether vowel length is critical to the maintenance of mutual intelligibility in ELF interactions among Nigerian Speakers of English and non-Nigerian speakers of English.

\section{Methodology}

\subsection{Materials and Method}

Six speech samples from six audio podcasts (broadcast materials) in which five Nigerian Yoruba speakers delivered speeches were used to determine the levels of intelligibility of Nigerian speakers of English. The choice of all speakers is not intended to be representative of all Nigerian Yoruba speakers; rather, it serves as a reflection of an elite subgroup of the population. Two reasons informed the choice of speakers. The main reason was that regardless of their identity as native Yoruba language speakers, the selected speakers are listened to by a wide audience both nationally and internationally. Thus, all five speakers, irrespective of their profession have a significant role and impact in mass communication and a significant presence on international platforms. Therefore, it is expected that communication for them would encompass international audiences, and so they are expected to be intelligible to a very wide audience. The second factor that determined the selection of these speakers was a consideration of their native language. All of them are Yoruba speakers. Preference was given to the Yoruba language because of its significance and reach. It is one of the three national languages used in Nigeria, and it is also used by a major ethnic group in Nigeria.

The six audio podcasts were presented to 100 international listeners (made up of non-Nigerian speakers from 25 nationalities (See Appendix B)) to transcribe. Two different criteria were used in selecting international listener participants. First, they had to be advanced English users, either undergraduate or graduate in order to ensure that they had reasonable competence in English. Based on the findings by Eisenstein and Berkowitz (1981) and Matsuura et al. (1999), non-native listeners with low proficiency may not be able to deal with intelligibility (dictation) tests. In order to control the effect of listeners' English proficiency level, all speakers of English from different linguistics backgrounds participating as listeners in this present study were required to have 7.0 score in International English Language Testing System (IELTS) or its equivalent, with 7.0 score in Listening, speaking and writing. This was considered to be essential because it ensures that the researcher gets reliable intelligibility test data in this present study. Secondly, listeners were not selected if they had prolonged experience communicating with Nigerian speakers of English. Gass and Varonis (1984) argue that 
familiarity with a non-native speaker's speech, a particular accent and a particular speaker all influence intelligibility.

Before the listening task, the listeners were informed of the speakers' name, their profession and the situational context that informed the existence of the podcasts. This was done in order to provide the listeners with a framework within which to focus their attention (Atechi, 2004) since it is rare in a real situation to listen to speech or conversation in a complete vacuum (Tiffen, 1974; Osle, 2013). However, the content of the speakers' text was not disclosed to the listeners. The six excerpts were played once to the listeners. The thought of playing the excerpts twice before the listening exercise was considered, but this idea was later dropped because it would have created an unnatural listening situation. In order to keep this as natural as possible, the podcasts (divided units of utterance) were played once.

The listeners heard the utterances in meaningful listening units and provided their responses on white sheets of paper by writing out the utterances in the dictation exercise. They were required to transcribe as precisely as possible what they heard in each of the six excerpts, and they were told to put a dash or a bracket sign where they did not understand, or simply guess what they thought they heard. Listeners transcriptions were used because they present more permanent and easily verifiable records for further study and analysis (Tiffen 1974; Atechi, 2004; Matsuura, Chiba and Ara 2012; Kashiwagi and Snyder, 2010).

After the completion of the listening and dictation exercise, listeners' transcriptions were carefully inputted manually into the computer, and checked manually again for accuracy. This enabled the researcher to have personal experience with the data. Various authors have raised a concern about using computer-assisted techniques (Cohen et al., 2011; Flick 2009). One of these concerns includes creating a distance between researchers and data. The listeners' transcriptions were used to locate instances of mismatch between the speakers' recordings and the listeners' transcribed text.

14 tokens of intelligibility breakdown caused by vowel length were identified. These 14 tokens were where intelligibility failed twenty or more listeners. Where only one to nineteen listener(s) failed to understand an utterance or a word, the failure has been discounted for the purposes of this analysis. The cut-off point used in this present study is in the same range with those that have been employed in previous studies. Tiffen (1974) and Atechi (2004) used two or more out of ten listeners as the cut-off point for the number of transcription errors that are significant. Therefore, in this current study, twenty is considered to be an approximate cut-off point for the number of transcription errors that are significant.

Before discussing the results, this paper will describe the terms and codes used in presenting the data. 


\subsection{Conventions and Terms Used in Presenting the Data}

\subsubsection{Tokens}

A Token represents a word that caused intelligibility breakdown for listeners. For example, consider Extract 2.1

\section{Extract 2.1 (Token 2)}

Context: / ... I am a producer, am a writer/ all my movies, I write them, and I produce them/and I play the lead [lid] character/ (Speaker 1, unit 9-11).

In this extract, the vowel in the word "lead" was pronounced with a short vowel. This caused problems with intelligibility for 41 listeners. The word "lead" here is a single token. It should also be noted that if a word occurs more than one time and cause intelligibility breakdown, this will be classified as separate tokens as indicated in the following extract from the podcast recordings.

\section{Extract 2.2}

Context: ...we want to be able/to have reasonable revenue from our resources/if you want our resources/we need that our laws and rules must be respected/we want infrastructure/ and if you can give us that/ yes, and we will pay for it either directly/or we will take loan at reasonable interest rate / (Speaker three, unit 9-11)

\subsection{Description for Codes used in tabulating the data in this study}

As the data were tabulated (see results throughout for deployment), the following codes were used.

NOL $=$ This code refers to the number of listeners that experienced intelligibility breakdown.

ORP $=($ Orthographic Representation of Phoneme). This signals instances in the data where listeners seemed to have orthographically represented the sound they heard. For example: in Token 10, speaker four pronounced the vowel in "introvert" as the back vowel [a] rather than the mid-central vowel quality [3:] which is expected in the reference accent (Received Pronunciation). Four listeners transcribed the word as "introvat" (phonetically transcribed as ['Intrəvat]). This transcription shows that the listeners recognised the sound [a] used by the speaker in the final syllable and they orthographically represented this. 
ORA= (Orthographic Representation Attempted). This code refers to instances in the data where listeners appeared to have orthographically represented part of a word apart from the syllable in which the pronunciation of a segmental feature varied from the referent accent (RP). For example: "introvert" pronounced as [' intrəvat] by speaker four was heard as "intro????" by some listeners. This listeners' response shows that part of the word or text (in this case, the first and the second syllable in introvert) has been orthographically represented but the syllable in which the pronunciation of the speaker has varied from the referent accent (RP) (in this case the final syllable in introvert) is not recognised. Another example that belongs to the code ORA are cases where listeners incorrectly orthographically represented a phoneme used by a speaker. For example: introvert pronounced as ['Introvat] was transcribed as "intellect" (phonetically transcribed as ['intəlekt]). This transcription demonstrates that the listeners recognised the [e] vowel in the final syllable instead of [a] used by the speaker.

SA = (Semantically Appropriate). This refers to instances where listeners seemed to have chosen words that make sense in their interpretation of utterances. For example: three listeners transcribed "I am an introvert person" as "I need the right person". This listeners" text or transcription shows that they have chosen words that are meaningful within the utterance but is not contextually appropriate as it does not fit the context in which the utterance was made.

$\mathbf{C A}=$ (Contextually Appropriate). This signals instances where listeners seemed to have relied on the context or circumstances in which the utterances were produced or cases where they may have resorted to their own previous background knowledge in their interpretation of utterances. For example: seven listeners transcribed "keep" (pronounced with a short vowel length by speaker one) as "get" in the phrase "...whoever you are, keep your head straight”.

$\mathbf{S C}=($ Syntactically Correct $)$. This code refers to cases where listeners seemed to have chosen words that are syntactically correct or appropriate. In other words, they have used their syntactic knowledge to decode the meaning of a word.

$\mathbf{N R}=$ (No response). This code refers to instances where listeners did not write anything for the word said by the speaker. For example, I am an introvert (pronounced as ['Intrəvat]) person transcribed as "I am an ?????? person". 


\section{Results}

The table provided below presents an overview of the vowel quantity or length that was identified, alongside the number of instances of intelligibility breakdown associated with each.

In this present study, there are fourteen tokens in which the length of a vowel may have contributed substantially to the occurrence of intelligibility breakdown. These tokens are shown in Table 3.1.

Table:3.1. Intelligibility breakdown involving vowel quantity

\begin{tabular}{|c|c|c|c|c|c|}
\hline $\begin{array}{l}\text { Token } \\
\text { no } \\
\end{array}$ & Speaker & Word & $\mathbf{R P}$ & Pronunciation & $\begin{array}{l}\text { Instances of } \\
\text { Breakdown }\end{array}$ \\
\hline 1 & One & any & /'zni// & [ع'ni:] & 36 \\
\hline 2 & One & lead & /li:d/ & [lid] & 41 \\
\hline 3 & One & keep & /ki:p/ & [kip] & 22 \\
\hline 5 & Three & strategic & /stra'ti:dzIk/ & [stro'tid3Ik] & 28 \\
\hline 7 & Three & reasonable & /'ri:zª nəb l// & ['rizºbob] & 37 \\
\hline 8 & Three & reasonable & /'ri:zªb放l/ & ['rizºbəbu] & 35 \\
\hline 11 & Five & deepen & $/ \mathrm{di}: \mathrm{p}^{\curvearrowright} \mathrm{n} /$ & [dipın] & 36 \\
\hline 12 & Five & skilled & /skild/ & [ski:d] & 46 \\
\hline 13 & Five & skilled & /skild/ & [ski:d] & 38 \\
\hline 14 & Five & living & /'livin/ & ['li:vin] & 60 \\
\hline 4 & Two & universalism & /ju:nI'v3:s $\mathrm{s}^{\mathrm{l}} \mathrm{Iz} \mathrm{z}^{\supseteq} \mathrm{m} /$ & [ju:nI'vas ${ }^{2} l z^{2} m$ ] & 64 \\
\hline 6 & Three & early & /'3: li / & ['aleI] & 78 \\
\hline 9 & Three & certain & /'s $3: t^{\ominus} \mathrm{n} /$ & ['satın] & 86 \\
\hline 10 & Four & introvert & /'Intrəv3:t/ & ['Intrəvat] & 50 \\
\hline
\end{tabular}

This paper will start by discussing straightforward cases. These include Tokens, 2, 3, 7, and 8 where the length of a vowel was the sole cause of the intelligibility breakdown. Thereafter, it will move on to discussing complex cases (Tokens 1, 5, 11, 12, 13, 14, 4, 6, 9, and 10) that involved a build-up of problems that caused the intelligibility breakdown.

In Token 2, Speaker one pronounced lead [li:d] as [lid] in the phrase "I play the lead character". Here, the short vowel was used, and this seems to have caused an intelligibility breakdown for 41 listeners. The extract shown below gives the wider context in which lead was misunderstood and listeners' interpretations of the word:

Extract 3.1

Context: / ... I am a producer, am a writer/ all my movies, I write them, and I produce them/and I play the lead [lid] the character/ (Speaker 1, unit 9-11). 


\begin{tabular}{|c|c|c|c|c|c|c|c|c|}
\hline & Listeners' responses & NOL & ORP & ORA & SA & CA & SC & NR \\
\hline 1 & I play the??? character & 28 listeners & & & & & & $\checkmark$ \\
\hline 2 & I play the new character & 1 listener & & $\checkmark$ & $\checkmark$ & $\checkmark$ & $\checkmark$ & \\
\hline 3 & I play the lid character & 11 listeners & $\checkmark$ & & & & & \\
\hline 4 & I play the lit character & 1 listener & $\checkmark$ & & & & & \\
\hline
\end{tabular}

As shown above, out of the 41 listeners, 28 left the space for the word blank. This could be because they cannot relate what they heard [lid] to the context. These listeners might be thinking that "lid" has nothing to do with the topic discussed. In (2), a listener"102 interpreted lead as "new", which may suggest that the listener substituted the word with something she is familiar with. In (3), and (4), the listeners' responses indicate that the vowel duration caused the intelligibility breakdown.

The remaining 59 listeners were able to transcribe the word "lead". One explanation for this could be that the linguistic background of listeners had in some way influenced the intelligibility of this word. In other words, listeners who transcribed "lead" correctly recognise that "lead character" collocate, whereas "lid character" is meaningless. They seem to have enough phonological clues to process this. Another reason could be that these listeners are familiar with accents that don't differentiate between the long and short vowel. The third explanation could be that the 59 listeners relied on the context (circumstances in which the utterances were produced) over pronunciation cues. From the context, lead would be the obvious word to have in the utterance because the speaker is talking about the role she played in a movie called "Jenifa". So, for these listeners, context seemed to overwrite pronunciation cues. But for the 41 listeners who had problems understanding the word "lead" (pronounced [lid]), the vowel duration was the issue (Jenkins 2000; 2002; Cruz 2003). This is because, despite much contextual information, they were guided by the pronunciation rather than the contextual cue. $^{103}$

In Token 3, Speaker one pronounced keep [ki:p] as [kip] in “... whoever you are, keep your head straight. Humility really matters you have to be humble...". A short vowel was used. The pronunciation of the word keep as [kip] caused intelligibility breakdown for 22 listeners who responded as follows:

${ }^{102}$ Listener 55 (Spanish)

${ }^{103}$ One might note that out of the 41 listeners who misunderstood lead, 4 were Norwegians (out of 6), 4 Germans (out of five), 12 British (out of 37) and 4 Americans (out of 5). This could have resulted from the fact that these speakers observe the vowel length distinction in their varieties. 


\begin{tabular}{|c|l|c|c|c|c|c|c|c|}
\hline & \multicolumn{1}{|c|}{ Listeners' responses } & NOL & ORP & ORA & SA & CA & SC & NR \\
\hline 1 & $\begin{array}{l}\text { Whoever you are, ????? } \\
\text { your head (straight) }\end{array}$ & 10 listeners & & & & & & $\checkmark$ \\
\hline 2 & $\begin{array}{l}\text { Whoever you are, put your } \\
\text { head straight }\end{array}$ & 1 listener & & & $\checkmark$ & $\checkmark$ & $\checkmark$ & $\begin{array}{l}\text { Whoever you are, get your } \\
\text { head (straight) }\end{array}$ \\
\hline 4 & $\begin{array}{l}\text { Whoever you are, } \text { kip your } \\
\text { head straight }\end{array}$ & 4 listeners & $\checkmark$ & & & & & \\
\hline
\end{tabular}

From the result shown in the table above, 10 listeners found the word unintelligible. This could be because they cannot relate what they heard to the context. Sometimes the listeners' have orthographically represented the vowel length used by the speaker as observed in example (4). The short duration of vowel produced by the speaker may have been responsible for the breakdown of intelligibility in this instance. In (2) and (3), it is possible that the listeners did not understand the pronunciation of "keep" but have chosen words that are semantically appropriate and syntactically correct. They may have used semantic information available in the sentence to work out what they heard.

In Token 7 and 8, speaker three pronounced the word reasonable ['ri:z ${ }^{\curvearrowright}$ nəb $\left.b^{\curvearrowright} l\right]$ as ['riz nəbo] on two occasions. This pronunciation caused intelligibility breakdown for listeners. The wider context in which reasonable occurred is given in the context below:

\section{Extract 3.2}

Context: /...we want to be able/ to have reasonable ['riz ${ }^{\curvearrowright}$ nəbo] revenue from our resources. /If you want our resources, / we need that our laws and rules must be respected. / We want infrastructure/ and if you can give us that, / yes, and we will pay for it either directly/ or we will take loan at reasonable ['riz ${ }^{\curvearrowright}$ nəbo] interest rate... (Speaker three, unit 10-17)

In this extract, speaker three said "reasonable" two times during his discussion, and each time, a short vowel was used in the first syllable. In addition to the vowel length, the speaker pronounced dark [1] as a close back vowel [ひ], a process Simo Bobda refers to as "vocalisation" (Simo Bobda 2007; Deterding 2014). The first token of reasonable (pronounced as ['riz ${ }^{\ni}$ nəbv]) caused intelligibility breakdown for 37 listeners who responded as follows: 


\begin{tabular}{|c|l|c|c|c|c|c|c|c|}
\hline & \multicolumn{1}{|c|}{ Listeners' responses } & NOL & ORP & ORA & SA & CA & SC & NR \\
\hline 1 & $\begin{array}{l}\text { to have????? revenue from } \\
\text { our resources }\end{array}$ & 27 listeners & & & & & & $\checkmark$ \\
\hline 2 & $\begin{array}{l}\text { to have listenable revenue } \\
\text { from our resources }\end{array}$ & 7 listeners & $\checkmark$ & & & & & \\
\hline 3 & $\begin{array}{l}\text { to have risknable revenue } \\
\text { from our resources }\end{array}$ & 1 listener & $\checkmark$ & & & & & \\
\hline 4 & $\begin{array}{l}\text { to have risk able revenue } \\
\text { from our resources }\end{array}$ & 2 listeners & $\checkmark$ & & & & & \\
\hline
\end{tabular}

From the findings, 27 listeners ${ }^{104}$ did not interpret the word reasonable. In (2), seven listeners ${ }^{105}$ heard reasonable as "listenable" while in (3), a listener ${ }^{106}$ heard the word as "risknable". These responses show a different vowel length in the initial syllable. In other words, their responses suggest that it is the duration of the vowel in the first syllable that caused problems for the listeners. In (4), two listeners ${ }^{107}$ heard reasonable as "risk able" which demonstrates a short vowel length in the first syllable.

The findings also reveal that apart from the 27 listeners who did not write anything for the word, all the listeners who attempted to guess the word recognised the dark [1] which suggests that the [1] vocalisation was not the cause of the intelligibility breakdown in this case. This may be because it is common in a range of Englishes for dark-1 to be pronounced as a close back vowel such as [ひ] (Wells, 1982:20). This happens especially in many varieties of British accents, South Eastern, and Cockney (Wells, 1994) and it is also found elsewhere in the world, including Inner Circle varieties such as those of New Zealand and Australia (Horvath and Horvath, 2001) as well as Outer Circles such as that of Nigeria (Simo Bobda, 2007) and Singapore (Tan, 2005).

Similar to Token 7, Speaker three in Token 8, repeated the word "reasonable" pronounced as [' riz nəbv] in the course of his speech. The word was qualifying "interest rate" in the phrase "...or we take loan at reasonable interest rate...". Even when speaker three used "reasonable" the second time during his speech, the word was still not intelligible to 35 listeners who responded as follows:

104 (11 British, 2 Americans, 4 Norwegians, 1 Italian, 4 German, 1 Greek, 1 Korean, 1Spanish, 1 Chinese and 1 Indian)

105 (5 British, 1 American, and 1 Polish)

106 (1 Brazilian)

107 (2 British listeners) 


\begin{tabular}{|c|l|c|c|c|c|c|c|c|}
\hline \multicolumn{1}{|c|}{ Listeners' responses } & NOL & ORP & ORA & SA & CA & SC & NR \\
\hline 1 & $\begin{array}{l}\text { or we take loan at???? } \\
\text { interest rate }\end{array}$ & 22 listeners & & & & & & $\checkmark$ \\
\hline 2 & or we take loan at ???????? & 8 listeners & & & & & & $\checkmark$ \\
\hline 3 & $\begin{array}{l}\text { or we take a low actionable } \\
\text { interest rate }\end{array}$ & 1 listener & & & & & & \\
\hline 4 & $\begin{array}{l}\text { or we take loan at his interest } \\
\text { rate }\end{array}$ & 3 listeners & & & $\checkmark$ & $\checkmark$ & & \\
\hline 5 & $\begin{array}{l}\text { or we will take long????? } \\
\text { transfer }\end{array}$ & 1 listener & & & & & & $\checkmark$ \\
\hline
\end{tabular}

The findings reveal that 11 listeners out of the 35 listeners heard the word reasonable correctly the first time in one context but did not interpret the word at the second occurrence. 20 listeners out of the 35 listeners did not hear the word reasonable in either occurrence. For example, a listener ${ }^{108}$ interpreted the first occurrence of reasonable as "riskable", but at the second occurrence of the word, he did not write anything for the word. In (3), a British listener heard reasonable at the first occurrence as "risk able", but at the second occurrence, he interpreted it as "actionable". This response shows that this listener heard the last syllable which further suggests that the [1] vocalisation was not an issue.

So, what is causing the problem in the two occurrences of the word "reasonable"? Could it be the length of the vowel used by the speaker in the initial syllable, or could it be the vocalisation of [1] as [ซ] in the final syllable, or a combination of these two? The analysis suggests that the use of a short vowel was the cause of intelligibility problems in the two occurrences of "reasonable", while the vocalisation of [1] was not an issue. An explanation for this is that [1] vocalisation occurred ten times in this study and in all its occurrences, it was not found to cause intelligibility breakdown for listeners. In addition, many of the listeners who misunderstood "reasonable" identified the final syllable "-able" and orthographically represented the length of vowel (short vowel) used by the speaker.

So far in this section, this paper has discussed straightforward cases where the length of a vowel was the sole cause of the intelligibility breakdown. Now, it will consider cases that involve an accumulation of factors that caused the intelligibility breakdown. In Token 1 , the vowel $/ \mathrm{i} /$ in the second syllable of "any" was longer than the normal duration. It sounded like /i:/, and this did change the stress from the initial syllable to the second syllable of the word in the phrase "I should be able to play any role". So "any" ['Eni] was pronounced [ $\varepsilon n ' i$ :] by Speaker one. The pronunciation of the word caused intelligibility problems for 36 listeners who wrote: "I should be able to play a new role". 
The listeners' transcriptions give the first vowel in "any" as stress less "a" and the second part as the adjective "new". So, this suggests that the stress difference and the vowel length difference caused intelligibility breakdown in this case.

The remaining 64 listeners interpreted the target word correctly in the utterance. One reason for this could be that in the process of interpretation, the listeners employed their knowledge of the world to activate the appropriate schema for their interpretation. This is one difference that was noted between the participants in this study and Jenkins' (1995; 2000) work. Jenkins noted that her participants rarely relied on the context and they usually relied on the conflicting acoustic signal or information. But, the participants in this present study, seemed to rely sometimes on the context and less on the acoustic signals, helping to reduce intelligibility. This could be because the participants in this current study are advanced learners of English.

In Token 5, Speaker three pronounced "strategic" /strə'ti:dzIk/ as [stro'tidzIk] in the phrase "who establish strategic partnership with China". Here one can notice a different vowel length [i] in the second syllable. A further breakdown shows that these 31 listeners did not identify the word "strategic". The intelligibility breakdown occurred probably because of the difference in vowel length on the second syllable. However, the earlier failure to understand the word "establish", which occurred before "strategic" may also have been a contributory factor.

In Token 11, deepen /di:pən/ was pronounced as [dipın] with a short vowel duration on the first syllable and a close front vowel [I] in the final syllable. The word caused intelligibility breakdown for 36 listeners who responded as follows:

\begin{tabular}{|c|l|c|c|c|c|c|c|c|}
\hline & \multicolumn{1}{|c|}{ Listeners' responses } & NOL & ORP & ORA & SA & CA & SC & NR \\
\hline 1 & $\begin{array}{l}\text { to dip in access of our } \\
\text { people to services }\end{array}$ & 23 listeners & $\checkmark$ & & & & & \\
\hline 2 & $\begin{array}{l}\text { to dipping access of our } \\
\text { people to services }\end{array}$ & 12 listeners & $\checkmark$ & & & & & \\
\hline 3 & $\begin{array}{l}\text { to differ in access of our } \\
\text { people to services }\end{array}$ & 1 listener & $\checkmark$ & & & & & \\
\hline
\end{tabular}

In this token, one can observe that those who misunderstood the word "deepen" orthographically represented the duration of vowel used by the speaker. This could suggest that the length of the vowel is a major problem in this case. Apart from the duration of the vowel in the initial syllable, which caused the main intelligibility breakdown, the quality of vowel [I] used by the speaker in the final syllable could be a contributory factor to the cause of the breakdown. This is because all those who misunderstood the word deepen 
also orthographically represented the sound used by the speaker as seen in examples such as "dip in", "dipping", and "differ in".

Token 12 and 13, also have multiple contributory factors: skilled is pronounced by Speaker five as [ski:d] with a long vowel length, a different vowel quality and non-realisation of [1]. This distinct pronunciation caused breakdown for 46 and 38 listeners respectively. Majority of these listeners came up with realisations such as "skied", "ski", and "key". These responses suggest that listeners have orthographically represented the quality and length of the vowel used by the speaker, in addition to the non-realisation of [1]. Thus, it can be suggested that vowel length difference is a contributory factor to the breakdown.

In Token 14, the vowel in the first syllable of "living" was pronounced with [i:] vowel and heard as "leaving", "easy" and "relieving". The responses suggest that a different vowel quality and length was used by the speaker. In cases such as this, it is hard to separate vowel quality from vowel length, as [I] differs from [i:] in both quality and length (Cruttenden, 2004:113). Therefore, the vowel may have interacted with the length to cause the breakdown.

Finally, in Table 3.1, we have Tokens 4, 6, 9, and 10. In Token 4, the third syllable of "universalism" was pronounced with the vowel variant [a] rather than [3:] and heard as realism, socialism, salism, idealism, and rationalism; in Token 6 , the first syllable of "early" was pronounced with [a] rather than [3:] and heard as I lived, I lay, I really, I reigned, I let, I led, and I; in Token 9, the first syllable of "certain" was pronounced with [a] rather than [3:] and heard as acting, act in, access, fracting, half, something, and satin and finally in Token 10, the final syllable of "introvert" was pronounced also with [a] and heard as intro ???, intellect, interrupt, vast, and intro vat. In these four tokens, it is hard to separate the vowel quality from its length as [a] differs from [3:] in both quality and length.

Even though, there appears to be a number of potential issues in ten (Tokens 1, 5, 11, 12, 13, 14, 4, 6, 9 and 10) of the 14 tokens that caused intelligibility breakdown due to the duration of vowel, this paper has considered Tokens 2, 3, 7 and 8 where obviously it was the vowel length that was the only attributable case of intelligibility breakdown. Based on these findings, it can be suggested that the distinct vowel length used in Token $1,5,11,12,13,14,4,6,9$ and 10 was at the very least a contributory factor in the breakdown of intelligibility. It might be the only factor, but, in this case, the paper is using the straightforward tokens to support the complex ones.

\section{Summary of Results}

As discussed above, the findings indicate that there were fourteen tokens in which the length of vowels contributed to intelligibility problems. 
This was also a finding in Jenkins (2000; 2002; 2007) and Zhang (2013). Most of the time, the Nigerian speakers in this present study did not maintain the distinction between long and short vowels. This may be related to the speakers' phonemic system, for instance Simo Bobda (1995) and Adetugbo (2009) observe that the high front vowels /i:/ and /I/ are neutralized as [i] in Nigerian English, suggesting that the vowel quantity is midway between the long /i:/ and the retracted /I/ of RP. The low front vowel/æ/ and the low back vowel /a:/ are neutralized into [a] in many cases. Likewise, the high back vowels / $/ /$ and /u:/ mostly occur as [u] in Nigerian English. The mid-back vowels /p/ and /o:/ are mostly realised as [0].

\section{Pedagogical Implications}

This section looks at the implications that can be drawn from this present study. Looking at the results of this study, it is clear that maintaining vowel length by speakers from Nigeria is more important and critical for international intelligibility.

\section{Limitations}

This study relied on speech samples from broadcast materials (audio podcast) that were later played to participants for evaluation (in form of transcription exercise) in terms of the intelligibility of the speech samples. In this way, the approach used may be said to be limited by the fact that it conceptualises intelligibility as a one-dimensional construct. While research methodology using this approach provides insights into intelligibility of ELF communication, it does not fully represent the "interactional construct (the interactive nature of talk) constantly negotiated between speakers and listeners" (Smith 1992:76). Notwithstanding, by using this approach, this study offers some insights about the processes of cross-cultural communication that may have been difficult to achieve with other approaches. For instance, while a face to face communication or interaction, which is more multi-dimensional in nature may have reflected the interactional process between speakers and listeners, this may not have given so many instances of intelligibility breakdown. This is because, in interactions where a listener encounters a problem in understanding the speaker's utterance, he/she might let the unrecognised utterance "pass", on the assumption that it will become either clear or redundant as talk progresses. This may also be to avoid coming across as rude. In this line of reasoning, Firth (1996:244) adds that it is not clear if these problems are genuinely missed by the hearer or whether they were heard and allowed to pass. The effect of a "let it pass" strategy can lead to the speakers ignoring the problematic utterance/word altogether and abandoning the topic or point being discussed given the dynamic nature of 
speech. For example, Mauranen (2006) only found six obvious instances of misunderstanding in her five hours of data from Finnish universities.

In contrast, the methodology used in the present study offers two crucial advantages: first, it enabled the researcher to investigate more precisely mismatches between the speakers' recordings and what the listeners heard. That is, it made it possible to identify all the words or phrases the listeners had not understood. Second, it presents more permanent and easily verifiable records for further study and analysis (Tiffen, 1974; Atechi 2004; Munro et al., 2006; Deterding, 2013). A future study could test the findings by using different research methods.

Second, the present study focused on the intelligibility of English spoken by educated Nigerian speakers', with a special focus on 100 international listeners. Thus, the findings of this research might not be applicable to all Nigerian English speakers, and to non-Nigerian speakers at different proficiency levels. Future studies may generate new insights and extend current knowledge by replicating this study with different groups of speakers and listeners.

\section{Conclusion}

The current research has indicated a rich and fascinating vein of work required to contribute to current knowledge and understanding of English intelligibility in the Nigerian context. Specifically, the research has added greatly to the understanding of the segmental features of pronunciation that hamper the intelligibility of Nigerian speakers when they communicate both in international and intranational contexts. As discussed, this understanding forms a useful foundation for reconsidering how English pronunciation is taught in Nigerian schools.

\section{References:}

1. Adetugbo, A. (2009) Problems of standardization and Nigerian English phonology. In: Dadzie, K. \& Awonusi, S. (eds.) Nigerian English: Influences and Characteristics. Lagos: Concept Publications. pp.179-199.

2. Atechi, S.N. (2004) The Intelligibility of Native and Non-Native English Speech: A Comparative Analysis of Cameroon English and American and British English. University of Chemnitz. Available at: http://d-nb.info/972345264/34 .

3. Cohen, L. L. Manion, and K. Morrison, (2011) Research Methods in Education, $7^{\text {th }}$ edition, USA and Canada: Routledge (first published: 1988)

4. Cruttenden, A. (2014) Gimson's Pronunciation of English. Routledge. 
5. Cruz, N. (2003) An exploratory study of pronunciation intelligibility in the Brazilian learner's English. The ESPecialist. 24pp.155-175.

6. Deterding, D. (2011) English language teaching and the lingua franca core in east Asia. In: Proceedings of the International Conference of Phonetic Sciences. pp.92-95.

7. Deterding, D. (2013) Misunderstandings in English as a Lingua Franca: An Analysis of ELF Interactions in South-East Asia. Berlin: De Gruyter Mouton.

8. Eisenstein, M. \& Berkowitz, D. (1981) The effect of phonological variation on adult learner comprehension. Studies in Second Language Acquisition. 4(1) pp.75-80.

9. Flick, U. (2009) The Sage Qualitative Research Kit: Collection. SAGE Publications Limited.

10. Firth, A. (1996) The discursive accomplishment of normality: On 'lingua franca English and conversation analysis. Journal of Pragmatics. 26(2) pp.237-259.

11. Gass, S. \& Varonis, E.M. (1984) The effect of familiarity on the comprehensibility of non-native speech. Language Learning. 34(1) pp.65-87.

12. Idowu, F. (2019) Pronunciation Intelligibility of Nigerian Speakers of English. European Scientific Journal, 15(20). Pp. 101-119

13. Jenkins, J. (2000) The Phonology of English as an International Language. Oxford: Oxford University Press.

14. Jenkins, J. (2003) World Englishes: A Resource Bookfor Students, $2^{\text {nd }}$ ed. London: Routledge.

15. Jenkins, J. (2007) English as a lingua franca: Attitude and identity. Oxford: Oxford University Press.

16. Jibril, M.M. (1982) Phonological Variation in Nigerian English. Unpublished $\mathrm{PhD}$ thesis, University of Lancaster

17. Kashiwagi, A. \& Snyder, M. (2010) Speech characteristics of Japanese speakers affecting American and Japanese listener evaluations. Teachers College, Columbia University Working Papers in TESOL \& Applied Linguistics. 10(1) pp.1-14.

18. Matsuura, H., Chiba, R. \& Fujieda, M. (1999) Intelligibility and comprehensibility of american andIrish englishes in japan. World Englishes. 18(1) pp.49-62.

19. Matsuura, Reiko and Satoshi (2012) International intelligibility of learner English.

20. O’Neal, G. (2015) ELF intelligibility: The vowel quality factor. Journal of English as a Lingua Franca. 4(2) pp.347-358 
21. Osle Ezquerra, Á. (2013) The Speech Intelligibility of English Learners of Spanish at Key Stage 4. Unpublished PhD thesis, Queen Mary University.

22. Simo Bobda, A. (1995) The phonologies of Nigerian English and Cameroon English. New Englishes: A West African Perspective. pp.248-268.

23. Simo Bobda, A.S. (2007) Some segmental rules of Nigerian English phonology. English World-Wide. 28(3) pp.279-310.

24. Tiffen, B.W. (1974) The Intelligibility of Nigerian English. Unpublished PhD thesis, University of London.

25. Wells, J.C. (1982) Accents of English. Cambridge: Cambridge University Press.

\section{Appendix A: Speakers List}

Table below shows a description of the background information of the six Nigeria Yoruba speakers whose talk (studio recordings) provided the speech material for the study.

\begin{tabular}{|c|c|c|c|c|c|}
\hline $\begin{array}{l}\text { Speaker } \\
\text { No. }\end{array}$ & $\begin{array}{l}\text { Gender } \\
\text { M/F }\end{array}$ & Age & Profession & $\begin{array}{l}\text { Source and context } \\
\text { of recording }\end{array}$ & $\begin{array}{l}\text { Educational } \\
\text { Background } \\
\end{array}$ \\
\hline One & $\mathrm{F}$ & 38 & Actress & $\begin{array}{l}\text { FAB Radio Aug } \\
2013 \text { (studio } \\
\text { interview) }\end{array}$ & Law graduate \\
\hline Two * & $\mathrm{M}$ & 80 & $\begin{array}{l}\text { Academician. } \\
\text { /diplomat }\end{array}$ & $\begin{array}{l}\text { UNESCO, February } \\
2010 \text { (interview at } \\
\text { panel conference) }\end{array}$ & University academic \\
\hline Three & $\mathrm{M}$ & 74 & Politician & $\begin{array}{l}\text { CCTV Africa June } \\
2013 \text { (studio } \\
\text { interview) }\end{array}$ & $\begin{array}{l}\text { Military \& } \\
\text { government officer }\end{array}$ \\
\hline Four & $\mathrm{F}$ & 48 & Actress & $\begin{array}{l}\text { GoldmyneTV Oct } \\
2013 \text { (studio } \\
\text { interview) }\end{array}$ & Economics graduate \\
\hline Five & $\mathrm{M}$ & 51 & Politician & $\begin{array}{l}\text { CNBC Africa } 2013 \\
\text { (interview) }\end{array}$ & Law graduate \\
\hline Six* 109 & M & 80 & $\begin{array}{l}\text { Academician } \\
\text { /diplomat }\end{array}$ & $\begin{array}{l}\text { CNBC Africa } 2010 \\
\text { (studio interview) }\end{array}$ & University academic \\
\hline
\end{tabular}

$109 *$ 'Speaker two' and 'Speaker six' is the same person. 


\section{Appendix B: Listeners List}

Key Terms of Major Fields

MCL- Media, Culture \& Language; PSY- Psychology; ECW- English and Creative Writing; BS- Business School; LS- life Sciences; DAN- Dance; EDSEducation; HUM- Humanities; SS- Social-Sciences

A brief description of the background information of the international listeners

\begin{tabular}{|c|c|c|c|c|c|c|}
\hline $\begin{array}{l}\text { Listener } \\
\text { Number }\end{array}$ & Gender & $\begin{array}{l}\text { Major } \\
\text { Field }\end{array}$ & Native language & $\begin{array}{l}\text { Place lived } \\
\text { btw 2-10 }\end{array}$ & Nationality & $\begin{array}{l}\text { Working language(s) } \\
\text { aside English }\end{array}$ \\
\hline 1 & Male & MCL & English & UK & British & Spanish, French \\
\hline 2 & Female & MCL & German & Austria & Austrian & None \\
\hline 3 & Female & MCL & English & UK & British & None \\
\hline 4 & Female & & Twi & Ghana & Ghanaian & None \\
\hline 5 & Male & PSY & English & UK & British & None \\
\hline 6 & Male & MCL & English & UK & British & None \\
\hline 7 & Female & MCL & German & Austria & Austrian & German, Polish \\
\hline 8 & Female & ECW & English & US & American & Armenian \\
\hline 9 & Female & PSY & English & UK & British & \\
\hline 10 & Male & $\mathrm{BS}$ & English & UK & British & Spanish, German, French \\
\hline 11 & Female & $\mathrm{BS}$ & Marathi & India & Indian & Hindi \\
\hline 12 & Female & $\mathrm{BS}$ & Twi & Ghana & Ghanaian & French \\
\hline 13 & Female & PSY & English & UK & British & None \\
\hline 14 & Female & LS & English & UK & British & None \\
\hline 15 & Female & MCL & English & UK & British & None \\
\hline 16 & Female & MCL & Portuguese & Brazil & Brazilian & Spanish \\
\hline 17 & Female & MCL & English & UK & British & French, Spanish \\
\hline 18 & Male & MCL & English & UK & British & None \\
\hline 19 & Female & MCL & English & UK & British & None \\
\hline 20 & Female & DAN & English & UK & British & None \\
\hline 21 & Female & EDS & English & UK & British & None \\
\hline 22 & Male & MCL & English & UK & British & None \\
\hline 23 & Female & $? ?$ & English & UK & British & None \\
\hline 24 & Female & MCL & English & UK & British & None \\
\hline 25 & Female & MCL & English & UK & British & Arabic \\
\hline 26 & Female & LS & Norwegian & Norway & Norwegian & German \\
\hline 27 & Female & MCL & French & France & French & Italian \\
\hline 28 & Female & MCL & Catalan & Catalonia & Spanish & Spanish \\
\hline 29 & Female & PSY & English & UK & British & None \\
\hline 30 & Female & MCL & Spanish & Spain & Spanish & French, Catalan \\
\hline 31 & Female & MCL & English & South Africa & South African & Afrikaans, Portuguese \\
\hline 32 & Male & DAN & Chichewa & Malawi & Malawian & French \\
\hline 33 & Female & MCL & Spanish & Spain & Spanish & Catalan \\
\hline 34 & Female & MCL & Italian & Italy & Italian & Spanish, German \\
\hline 35 & Female & MCL & English & UK & British & None \\
\hline 36 & Female & MCL & English & UK & British & Arabic \\
\hline 37 & Female & $? ?$ & English & UK & British & None \\
\hline
\end{tabular}




\begin{tabular}{|c|c|c|c|c|c|c|}
\hline 38 & Female & EDS & English & UK & British & Somali \\
\hline 39 & Female & MCL & English & UK & British & Arabic \\
\hline 40 & Female & $? ?$ & English & UK & British & Somali \\
\hline 41 & Female & EDS & English & UK & British & French, Italian \\
\hline 42 & Male & MCL & English & Saudi Arabia & Saudi Arabian & Urdu \\
\hline 43 & Male & EDS & English & UK & British & None \\
\hline 44 & Female & MCL & English & UK & British & None \\
\hline 45 & Female & MCL & Catalan & Spain & Spanish & Spanish, French \\
\hline 46 & Male & $? ?$ & Polish & Poland & Polish & None \\
\hline 47 & Female & MCL & English & UK & British & \\
\hline 48 & Female & BS & English & UK & British & Creole \\
\hline 49 & Male & MCL & Norwegian & Norway & Norwegian & None \\
\hline 50 & Male & MCL & English & US & American & None \\
\hline 51 & Female & MCL & Greek & Greece & Greek & German, French \\
\hline 52 & Male & MCL & Korean & South Korea & South Korean & None \\
\hline 53 & Female & MCL & French & France & French & None \\
\hline 54 & Female & $? ?$ & Spanish & Spain & Spanish & None \\
\hline 55 & Female & EDS & Spanish & Spain & Spanish & French \\
\hline 56 & Female & MCL & Mandarin Chinese & China & Chinese & None \\
\hline 57 & Male & MCL & Nepali & India & Nepalese & None \\
\hline 58 & Male & MCL & Polish & Poland & Polish & French, Portuguese \\
\hline 59 & Female & MCL & German & Germany & German & Spanish \\
\hline 60 & Female & ECW & Norwegian & Norway & Norwegian & None \\
\hline 61 & Female & DAN & Bengali & India & Indian & Hindi, Bengali \\
\hline 62 & Male & MCL & Persian & Iran & Iranian & None \\
\hline 63 & Female & MCL & Tamil & India & Indian & None \\
\hline 64 & Female & MCL & Norwegian & Norway & Norwegian & German \\
\hline 65 & Male & MCL & English & UK & British & Krio \\
\hline 66 & Male & MCL & Chichewa & Malawi & Malawian & None \\
\hline 67 & Female & MCL & German & German & German & French, Spanish \\
\hline 68 & Female & MCL & English & UK & British & Somali, Arabic \\
\hline 69 & Female & $? ?$ & German & Germany & German & None \\
\hline 70 & Female & MCL & German & Italy & Italian & Spanish, Italian, German \\
\hline 71 & Female & ECW & Tamil & India & Indian & None \\
\hline 72 & Female & HUM & Tamil & India & Indian & None \\
\hline 73 & Female & MCL & Arabic & Saudi Arabia & Saudi Arabian & None \\
\hline 74 & Female & MCL & Tamil & Germany & Indian & German \\
\hline 75 & Male & EDS & Chichewa & Malawi & Malawian & None \\
\hline 76 & Male & EDS & Chichewa & Malawi & Malawian & Malawi, Chichewa \\
\hline 77 & Female & SS & Italian & Italy & Italian & None \\
\hline 78 & Female & SS & English & US & American & Spanish \\
\hline 79 & Male & HUM & Arabic & Palestine & Palestinian & None \\
\hline 80 & Male & LS & Bengali & India & Indian & Hindi \\
\hline 81 & Female & EDS & Thai & Thailand & Thai & French \\
\hline 82 & Female & HUM & German & Germany & German & French \\
\hline 83 & Female & PSY & English & Singapore & Singaporean & Mandarin, Malay \\
\hline 84 & Male & BS & Twi & Ghana & Ghanaian & French \\
\hline 85 & Female & EDS & Mandarin Chinese & China & Chinese & None \\
\hline
\end{tabular}




\begin{tabular}{|l|l|l|l|l|l|l|}
\hline 86 & Female & PSY & Norwegian & Norway & Norwegian & Urdu \\
\hline 87 & Female & MCL & Russian & Russia & Russian & Ukrainian \\
\hline 88 & Female & MCL & Russian & Ukraine & Russian & German \\
\hline 89 & Male & ECW & German & Germany & German & None \\
\hline 90 & Female & PSY & Norwegian & Norway & Norwegian & Swedish, Danish \\
\hline 91 & Male & $? ?$ & Twi & Ghana & Ghanaian & French, German \\
\hline 92 & Female & EDS & English & UK & British & None \\
\hline 93 & Female & EDS & English & UK & British & None \\
\hline 94 & Female & MCL & English & UK & British & Spanish, French \\
\hline 95 & Female & PSY & English & UK & British & None \\
\hline 96 & Female & PSY & English & UK & British & None \\
\hline 97 & Female & PSY & English & US & American & None \\
\hline 98 & Female & MCL & Greek & Greece & Greek & French \\
\hline 99 & Female & PSY & English & US & American & None \\
\hline 100 & Female & PSY & Romania & Romania & Romania & German \\
\hline
\end{tabular}

